\title{
Post-depositional modification of stable water isotopes in winter snowpacks in the Canadian Rocky Mountains
}

\author{
K.E. SINCLAIR, S.J. MARSHALL \\ Department of Geography, University of Calgary, 2500 University Drive NW, Calgary, Alberta T2N 1N4, Canada \\ E-mail: kate.sinclair@ucalgary.ca
}

\begin{abstract}
To assess the seasonal stability of the $\delta^{18} \mathrm{O}$ stratigraphy in winter snowpacks in the Canadian Rocky Mountains, snow pits were sampled over three accumulation seasons at two field sites. These sites, Opabin and Haig Glaciers, are $\sim \mathbf{1 6 0} \mathrm{km}$ apart at similar elevations and represent windward and lee-slope environments respectively. At both sites, snow pits were sampled at one glacier and one forefield location throughout each accumulation season. Intra-seasonal changes in $\delta^{18} \mathrm{O}$ at each site were examined to determine the extent of post-depositional modification of isotope stratigraphies. At both glacier sites, there was minimal temporal change before the onset of spring melt in all years. In addition, the similar structure of $\delta^{18} \mathrm{O}$ profiles from both glacier sites suggests that regional controls govern the isotopic composition of solid-phase precipitation across the study area. At forefield locations, the absence of an insulating layer of ice at the base of the snowpack allowed for vapour transport and post-depositional modification of the seasonal $\delta^{18} \mathrm{O}$ signal. This did not result in consistent changes to the mean $\delta^{18} \mathrm{O}$, deuterium excess and $\delta \mathrm{D}-\delta^{18} \mathrm{O}$ regression line slopes in the lower layers of snow, and the observed smoothing of $\delta^{18} \mathrm{O}$ profiles was less than that simulated by applying a diffusion model to these snowpacks.
\end{abstract}

\section{INTRODUCTION}

Stable water isotopes $\left(\delta^{18} \mathrm{O}\right.$ and $\left.\delta \mathrm{D}\right)$ in precipitation are governed by the advective transport and condensation history of precipitation-bearing weather systems and, in particular, the in-cloud temperature during condensation (Dansgaard, 1964). These characteristics are recorded in solid-phase precipitation, so that snowpacks potentially provide a cumulative record of winter precipitation events. In addition, the preservation of annual isotopic cycles in regions where the snowpack survives the summer melt season has enabled the reconstruction of high-resolution temperature records from firn and ice cores. However, the interpretation of $\delta^{18} \mathrm{O}$ and $\delta \mathrm{D}$ profiles in these records requires a critical assessment of the influence of postdepositional processes on the integrity of the isotope stratigraphies (Stichler and Schotterer, 2000). On a seasonal timescale, these processes act to diffuse isotopic signals from individual accumulation events, smoothing the isotopic variability retained in the snowpack stratigraphy Judy and others, 1970; Krouse and Smith, 1972; Cooper, 1998). On longer timescales, the same mechanisms reduce the interannual variability preserved in ice-core records, complicating the use of stable water isotopes as paleothermometers.

Before the onset of spring melt, the physical processes most likely to control the post-depositional modification of isotope stratigraphies at the surface of alpine snowpacks are wind scour and sublimation. Because winter snow tends to be low-density, it is more susceptible to wind transport and redistribution (Naftz and others, 2004). Sites that experience a significant amount of wind scour in winter months therefore tend to be deprived of the light isotopic species associated with cold condensation temperatures (Fisher and others, 1983). The effects of surface sublimation are confined to the upper boundary of snowpacks and are most pronounced when there are extended dry periods with low atmospheric humidity (Stichler and Schotterer, 2000; Stichler and others, 2001; Neumann and others, 2005). Under these conditions, sublimation leaves surface snow enriched in heavy isotopic species (Moser and Stichler, 1975).

At the ground-snow interface of alpine snowpacks, the input of geothermal heat may promote strong temperature gradients, vapour transport, recrystallization and depth-hoar formation. In previous studies, this has been associated with an increased concentration of heavy isotopes in the lowest layers of the snowpack (Friedman and others, 1991; Sommerfeld and others, 1991; Sturm and Benson, 1997; Hachikubo and others, 2000). Finally, while diffusion in the solid phase is negligible in the time frame of seasonal snowpacks, vapour-phase diffusion within the snow matrix is 1000 times faster and acts to reduce isotopic gradients during sublimation and redeposition in snow and firn (Bolzan and Pohjola, 2000; Johnsen and others, 2000; Helsen and others, 2005).

A significant degree of post-depositional modification via any of these processes compromises the interpretation of precipitation isotopes both on a seasonal timescale and in longer-term analyses. For this reason, we aim to assess the temporal stability of winter $\delta^{18} \mathrm{O}$ stratigraphies in the Canadian Rocky Mountains to determine both the cause and extent of any post-depositional modification. We also consider the spatial reproducibility of the winter $\delta^{18} \mathrm{O}$ profiles. A high degree of similarity between stable isotopes on windward and lee slopes of this mountain range, across a broad spatial area, offers the possibility of identifying regional accumulation events in winter isotope stratigraphies. This would, in turn, lend insight into the relative importance of weather system types that bring snow to the alpine watersheds of the region. 

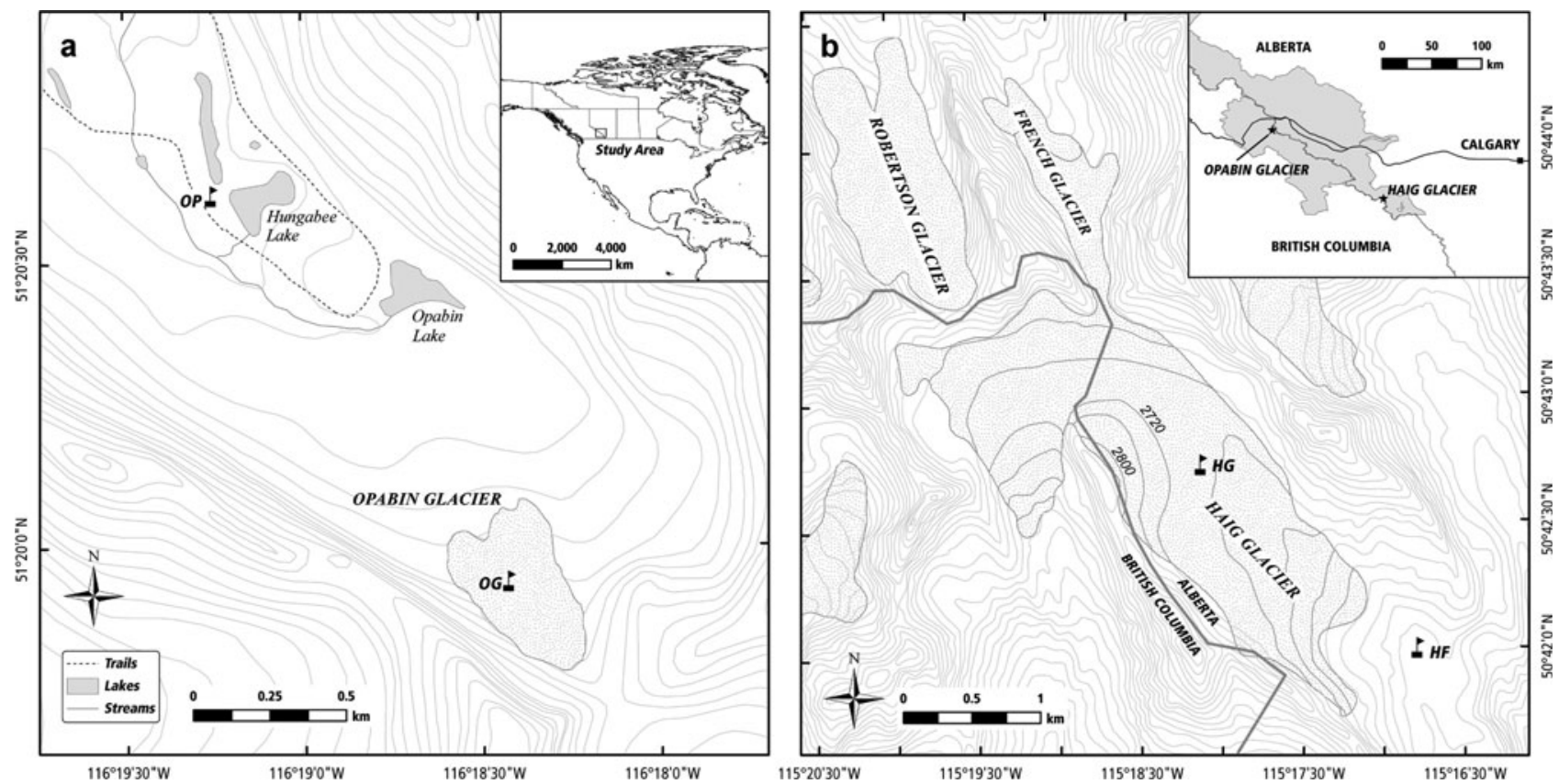

Fig. 1. (a) Opabin Plateau and Opabin Glacier showing snow-pit sites OG (Opabin Glacier) and OP (Opabin Plateau). The inset shows the location of the study sites in North America. (b) Haig Glacier showing snow-pit sites HG (Haig Glacier) and HF (Haig Forefield). The inset shows the relative locations of Haig and Opabin Glaciers in the Canadian Rocky Mountains.

\section{FIELD SITES AND ANALYSIS}

The Canadian Cordillera comprises the Rocky, Columbia and Coast Mountain ranges extending from the United States border into northern British Columbia. These mountains have a glaciated area of approximately $38613 \mathrm{~km}^{2}$ (Ommanney, 2002) and experience a long snow accumulation season, lasting generally from October to late May. Our field studies focus on the Rocky Mountains, which comprise the continental divide at the eastern edge of the Canadian Cordillera. The two field sites selected for this study are glaciated catchments in the Rocky Mountains that are part of long-term studies of glacier mass balance, surface energy-balance processes and alpine hydrology (Fig. 1). Opabin Glacier is located in Yoho National Park, British Columbia, between 2300 and 2450 ma.s.l. on the westfacing (windward) slopes of the Rocky Mountains. Haig Glacier is an east-facing (lee-slope) environment in Peter Lougheed Provincial Park, Alberta. It is the largest arm of the southernmost icefield in this region and has an area of approximately $2.9 \mathrm{~km}^{2}$. The upper glacier ( 2800 m a.s.l.) is a broad, gently sloping plateau that flows east from the North American continental divide to approximately $2430 \mathrm{~m}$ a.s.I.

These sites were visited throughout the 2004/05, 2005/06 and 2006/07 snow accumulation seasons (October-June) and into the summer melt season. In 2004/05, work was focused on Haig Glacier and a late-season snow pit was sampled at Opabin Glacier. In 2005/06, snow pits were sampled intensively at both sites through the accumulation season, and in 2006/07 mid- and late-winter snow pits were sampled at both sites. At Haig Glacier, snow pits were dug in the vicinity of two automatic weather stations (AWSs). One AWS is located mid-glacier near the equilibrium line (HG; Fig. 1b), and the other is approximately $100 \mathrm{~m}$ from the glacier terminus on the forefield moraine (HF; Fig. 1b). Similarly, at Opabin Glacier, snow pits were dug near an ultrasonic depth gauge (UDG) at a site near the centre of the glacier (OG; Fig. 1a) and on the deglaciated Opabin Plateau near an AWS (OP; Fig. 1a). The lower, HF and OP sites are referred to as forefield sites, while the upper, HG and OG sites are referred to as glacier sites.

The dates, names, depths and number of samples $(n)$ from all snow pits are shown in Table 1. On each visit, snow-pit walls exposed the cumulative seasonal precipitation and each snow-pit wall was sampled for density, stable-isotope analysis and the temperature profile. At the glacier sites, snow pits were dug back to the summer melt surface, and at the forefield sites snow pits were dug to the moraine surface. At the HF site, this consists of exposed rock, but at the OP site there is a shallow layer of soil and vegetation overlying the moraine.

Samples were taken upward from the ground/glacier using a $100 \mathrm{~cm}^{3}$ steel sampler at $10 \mathrm{~cm}$ vertical resolution in 2004/05 and $5 \mathrm{~cm}$ vertical resolution in 2005/06 and 2006/ 07. Snow samples were bagged and transported to Calgary frozen, where they were melted at room temperature and bottled for stable-isotope analysis. Analysis was conducted at the University of Calgary Stable Isotopes Laboratory using the $\mathrm{CO}_{2}-\mathrm{H}_{2} \mathrm{O}$ equilibration technique for $\delta^{18} \mathrm{O}$ (Epstein and Mayeda, 1953) and chromium reduction for $\delta \mathrm{D}$. In both cases, a dual-inlet isotope-ratio mass spectrometer was used to determine $\delta$ values, which are reported in per mil (\%o) notation relative to Vienna Standard Mean Ocean Water (V-SMOW). Accuracies are generally better than $\pm 0.2 \%$ for $\delta^{18} \mathrm{O}$ and $\pm 2.0 \%$ for $\delta \mathrm{D}$.

\section{RESULTS}

\section{Glacier sites}

Figures 2 and 3 show the $\delta^{18} \mathrm{O}$ and temperature profiles from the HG and OG sites in the 2005/06 accumulation season for all snow pits prior to spring melt and for the first isothermal snow pit at each site. The depth is represented as 
Table 1. Snow-pit names, dates, depths and total number of samples ( $n$ ) for the 2004/05, 2005/06 and 2006/07 seasons. Note that snow pits are numbered consecutively, followed by the abbreviated year ('05' for 2004/05 or ' 06 ' for 2005/06) (e.g. HF105 is the first snow pit in the 2004/05 accumulation season at the Haig Forefield)

\begin{tabular}{lccc}
\hline Sampling date & Snow pit & Depth & Snow pit \\
$\mathrm{cm}$ & $\mathrm{cm}$ & $\begin{array}{c}n \\
\mathrm{~cm}\end{array}$ \\
\hline
\end{tabular}

\section{4/05}

30 Jan. 2005

5/6 Mar. 2005

12 Apr. 2005

30 May/1 June 2005

18 May 2005

13 June 2005

Total $n$ :

2005/06

29/30 Oct. 2005

21 Feb. 2006

18 Mar. 2006

23 Apr. 2006

13 June 2006

1 July 2006

11 Oct. 2005

23 Nov. 2005

9 Jan. 2006

30 Jan. 2006

5 Mar. 2006

1 Apr. 2006

20/21 Apr. 2006

8/9 May 2006

21 June 2006

Total $n$ :

2006/07

26 Jan. 2007

12 Apr. 2007

27 Feb. 2007

18 Apr. 2007

Total $n$ :

$\begin{array}{lc}\text { HF105 } & 108 \\ \text { HF205 } & 140 \\ \text { HF305 } & 177 \\ * \text { HF405 } & 66\end{array}$

11

18

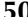

55

165

185

185

HF106
HF206
HF306
HF406

OP306

OP406

OP506

OP606

OP706

*OP806

46

94

112

122

143

132

151

HF107

HF207

OP107

OP207

50

143

210

128

268

1
4
7
7

HG205
HG305
*HG405
OG105
*OG205

\section{8}

209

273

207

263

164

21

21

27

20

26

37

152

$\begin{array}{lll}\text { HG106 } & 123 & 24 \\ \text { HG206 } & 262 & 52\end{array}$

$\begin{array}{lll}\text { HG306 } & 319 & 64\end{array}$

$\begin{array}{lll}\text { HG406 } & 353 & 70\end{array}$

*HG506 240

*HG606 159

$\begin{array}{lll}\text { OG106 } & 109 & 16\end{array}$

OG206 $159 \quad 28$

$\begin{array}{lll}\text { OG306 } & 224 & 39\end{array}$

$\begin{array}{lll}\text { OG406 } & 290 & 49\end{array}$

$\begin{array}{lll}\text { OG506 } & 303\end{array}$

$\begin{array}{lll}\text { OG706 } & 318 & 63\end{array}$

$\begin{array}{lll}\text { OG806 } & 346 & 34\end{array}$

*OG906 $224 \quad 43$

270

596

$\begin{array}{cccc}14 & \text { HG107 } & 263 & 26 \\ 41 & \text { HG207 } & 305 & 56 \\ 25 & \text { OG107 } & 266 & 53 \\ 26 & \text { OG207 } & 355 & 69 \\ \mathbf{1 0 6} & & & \mathbf{2 0 4}\end{array}$

*Isothermal snow pit.

snow water equivalent (SWE) and is measured from the base of the snow pit to the surface, and error bars show the estimated analytical error. Key stratigraphic features are labeled as reference points to enable cross-pit comparisons. The most positive (isotopically heavy) reference points are labeled as letters, and the most negative (isotopically light) reference points are numbered consecutively from the base of the snowpack to the surface. As we did not sample continuously, we cannot be sure that we measured the true isotopic peaks (either negative or positive). These reference points do serve, however, as a useful guide, particularly for the 2005/06 and 2006/07 accumulation seasons where the $5 \mathrm{~cm}$ sampling resolution captured the majority of the snowpack. This resolution is sufficient to track the isotopic character of major snowfall events through the accumulation season, but small snow accumulation events will be missed or averaged with larger events.

In addition to the fact that some isotopic variability may not have been captured by our sampling resolution, the stratigraphic features labeled in Figures 3 and 4 are also observed at different depths due to (1) differences in settling rates that cause local density variations; (2) irregularities in the surface of the moraine or glacier at the base of the snow pit, and snow surface undulations; (3) snow redistribution by wind; and (4) error associated with depth measurements while sampling. To minimize these depth variations, we confined our snow-pit sites to within a $30 \mathrm{~m}$ radius of each AWS or UDG, while ensuring that we sampled undisturbed snow on each site visit.

There was a wide range in $\delta^{18} \mathrm{O}$ values at both glacier sites, with the maximum seasonal range in $\delta^{18} \mathrm{O}$ averaging $-14.8 \%$ and $-15.9 \%$ at Haig and Opabin Glaciers respectively. The sawtooth nature of the profiles at both sites likely reflects variable temperature characteristics and vapour source regions of the succession of winter storms that bring snow to the region. There was also a high degree of temporal continuity in $\delta^{18} \mathrm{O}$ profiles at the glacier sites across all accumulation seasons and no indication of widespread post-depositional change. The mean shift in reference-point values at Haig Glacier was 1.1\%o, 1.6\%o and $1.5 \%$ in 2004/05, 2005/06 and 2006/07 respectively. At Opabin Glacier, mean reference-point shifts were $1.8 \%$ in $2005 / 06$ and $1.2 \%$ in $2006 / 07$. Although these values are subject to the sources of error discussed above, they do provide some quantitative measure of the extent of post-depositional change and are considered to be relatively minor in the context of the high variability in $\delta^{18} \mathrm{O}$ at these sites. 


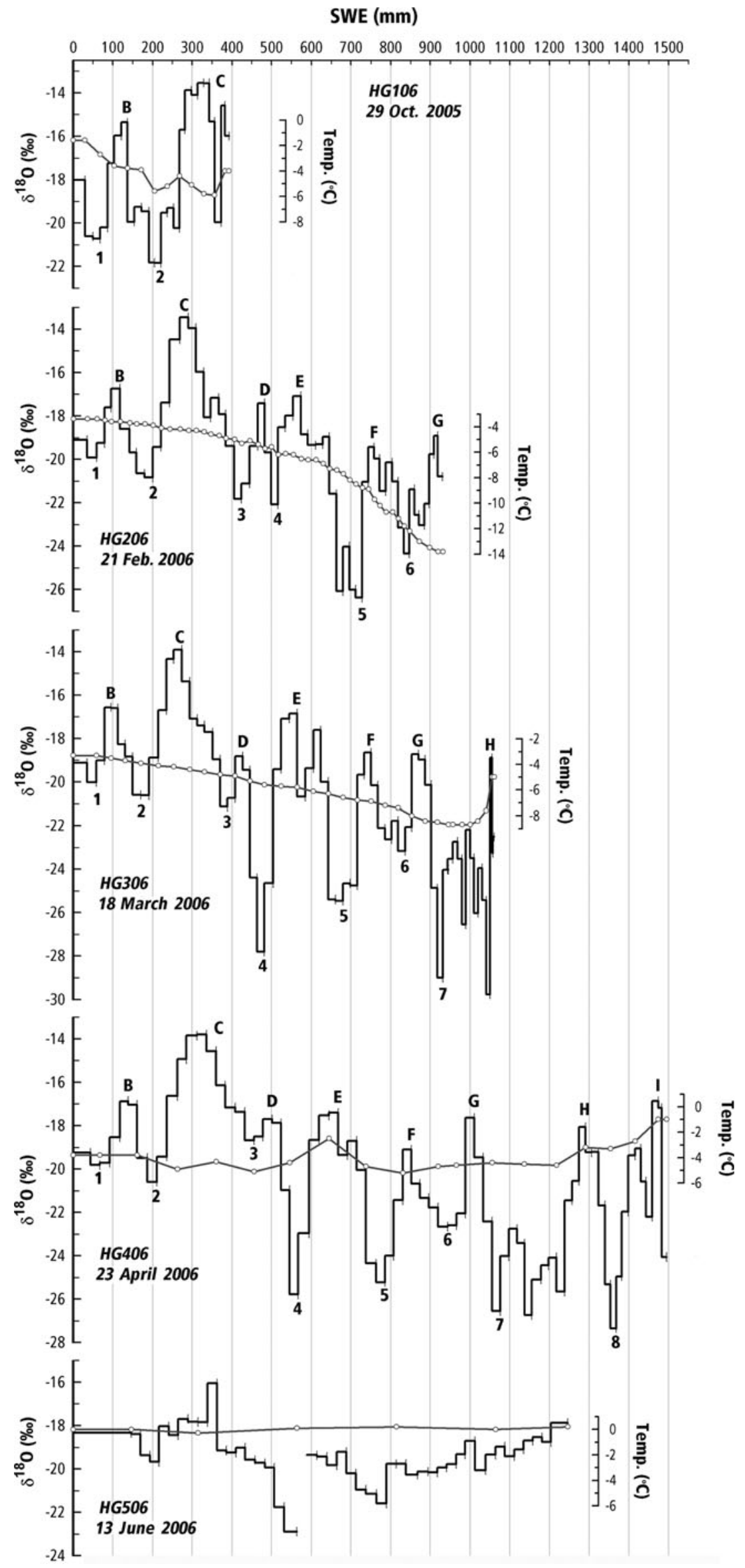

Fig. 2. $\delta^{18} \mathrm{O}$ stratigraphies and temperature profiles of HG snow pits from the 2005/06 accumulation season. HG606 (1 July) is not shown, as the snowpack had become isothermal by HG506 (13 June). The data gap in HG506 is the result of a damaged sample. 

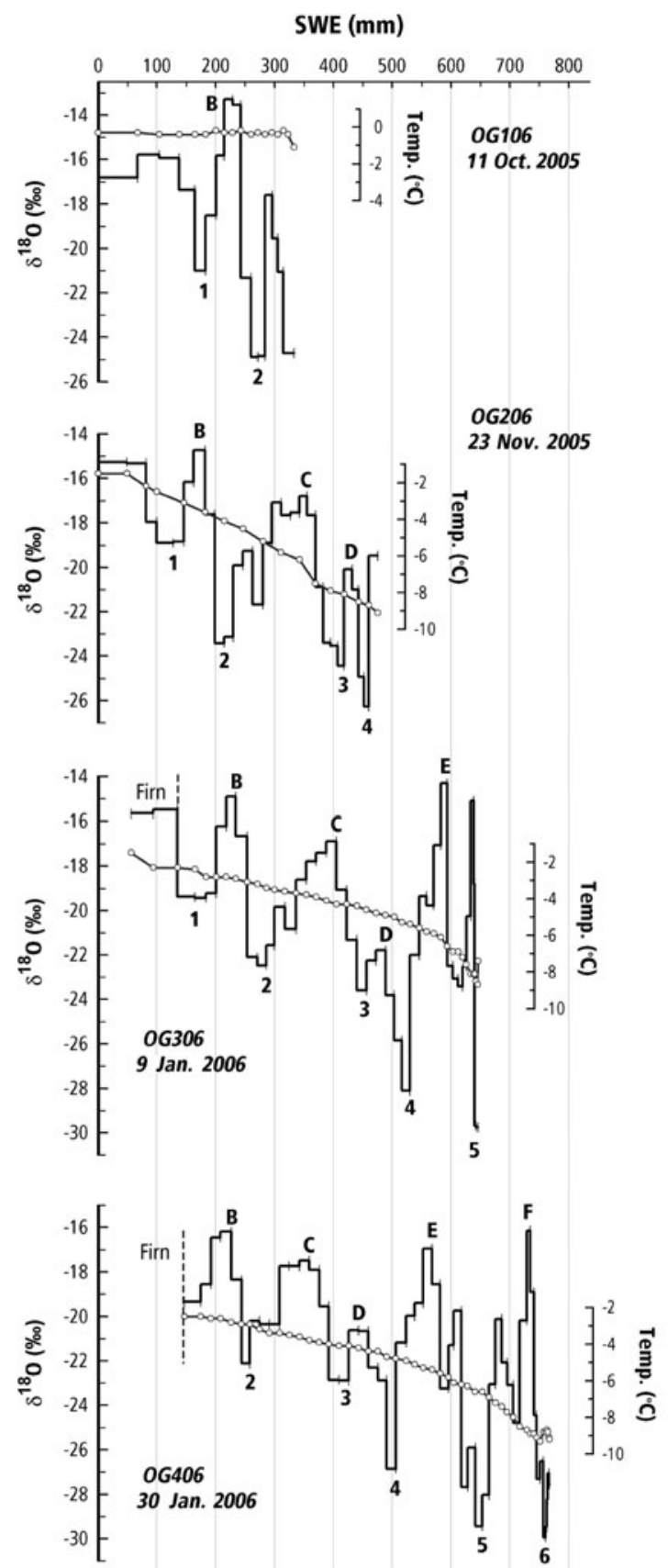

SWE (mm)
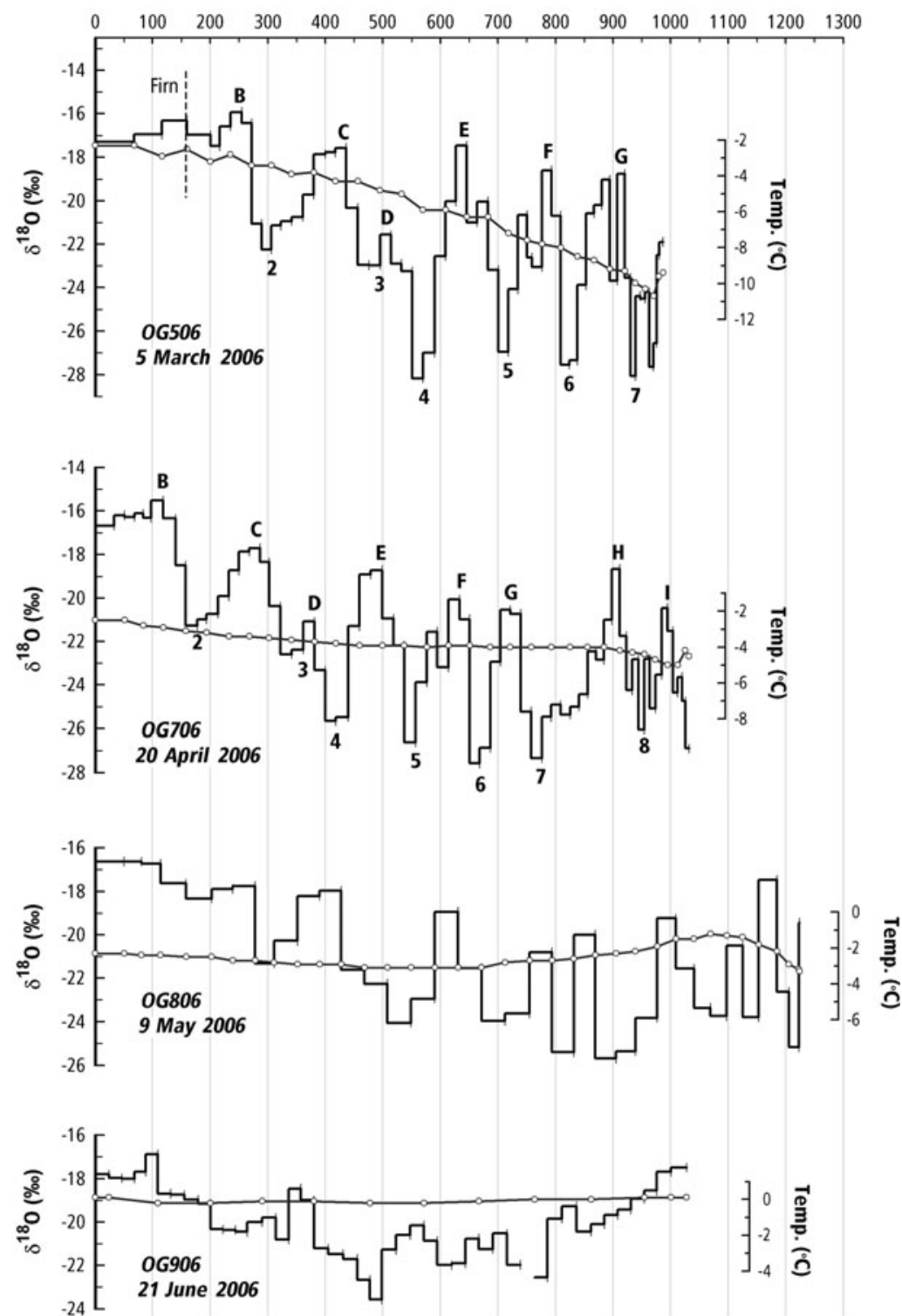

Fig. 3. $\delta^{18} \mathrm{O}$ stratigraphies and temperature profiles of all OG snow pits from the 2005/06 accumulation season. A dense layer of firn occurred at the base of OG306-OG506 below $\sim 150 \mathrm{~mm}$. This was not sampled in OG406, but the average $\delta^{18} \mathrm{O}$ of this layer from previous and subsequent snow pits was $-16.3 \%$. Due to the isotopic homogeneity associated with snow that has survived summer melt, it is expected that the $\delta^{18} \mathrm{O}$ of firn in OG406 would fall within this range.

There was also a strong correspondence between $\delta^{18} \mathrm{O}$ profiles at Haig and Opabin Glaciers in all years of the study, with the same stratigraphic features identified at both locations (Figs 2 and 3 ). The mean $\delta^{18} \mathrm{O}$ values of each reference point for the $\mathrm{HG}$ and OG sites are shown in Figure 4 . The mean reference-point values were calculated using data from all pre-melt snow pits at each site, apart from for 2004/05 when only one snow pit was sampled at the OG site. For this reason, we compare reference points from OG105 with the closest pre-melt HG snow pit, HG305. A linear regression between these data shows a strong relationship between reference points, with an $R^{2}$ of 0.79 . The average deviation of all data in Figure 4 from the line of best fit was $2.1 \%, 2.5 \%$ and $3.5 \%$ in the three consecutive accumulation seasons. A matched-pairs $t$ test was also performed to assess whether there is a statistical difference between these datasets. The results of this indicate that there is no significant difference between the HG and OG reference points at $95 \%$ confidence $(n=41 ; p=0.0139)$. While we expect some differences between $\delta^{18} \mathrm{O}$ values at Haig and Opabin Glaciers due to local atmospheric and topographic influences and variations in air-mass trajectory during individual storms (Sinclair and Marshall, unpublished information), the similarity in the structure of $\delta^{18} \mathrm{O}$ profiles at these sites indicates that the same major storm systems bring snow to both Opabin and Haig Glaciers. 


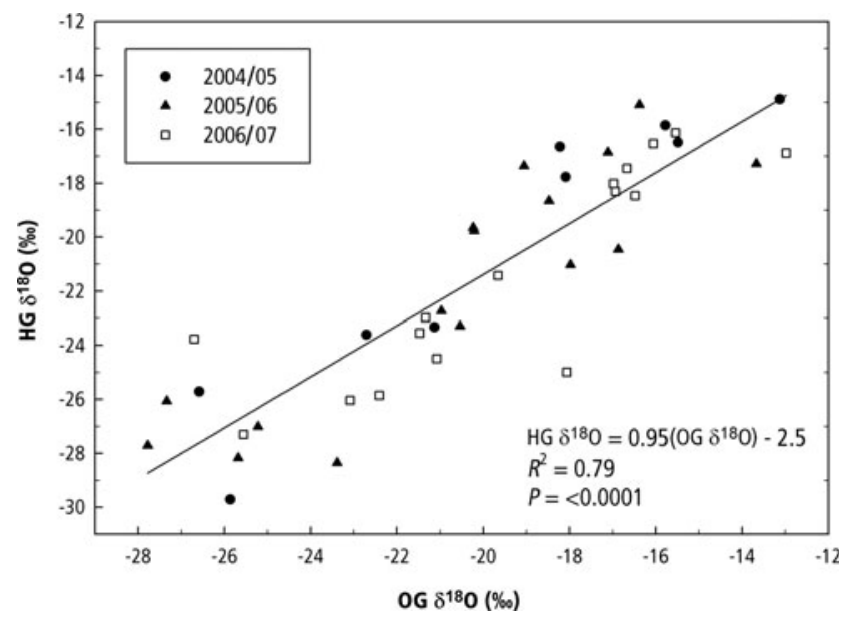

Fig. 4. Scatter plot of the mean reference-point values from $\mathrm{HG}$ and OG snow pits from each accumulation season. The line of best fit is shown along with the equation of this line, and the $R^{2}$ and $p$ values from the regression analysis.

\section{Forefield sites}

Figures 5 and 6 show $\delta^{18} \mathrm{O}$ profiles from the 2005/06 accumulation season at the HF and OP sites. These were sampled within 24 hours of the snow pits from the glacier sites shown in Figures 3 and 4, apart from OP606 when there was no corresponding OG snow pit.

At the HF site, there was considerable seasonal modification of the $\delta^{18} \mathrm{O}$ profiles, particularly in the lowest $250 \mathrm{~mm}$ of SWE. A highly depleted layer $(-30.7 \%$ ) at $253 \mathrm{~mm}$ in HF206 did not appear in the isotopic record from the HG site at this time, but it spanned two samples and we believe this was a genuine feature of the snowpack, rather than a sampling error or stochastic variability. It may reflect a snowfall event that was local to the glacier forefield, or wind scour may have prevented preservation of this event at the HG site. This depleted layer was no longer present in HF306 ( 25 days later), and the isotopic profile of the lower snowpack was highly modified over this time interval, showing an almost inverse structure to the previous snow pit. Also evident in HF306 is a marked increase in $\delta^{18} \mathrm{O}$ in the lowest $50 \mathrm{~mm}$ of the snowpack, a feature that is persistent in HF406. A trend to more positive $\delta^{18} \mathrm{O}$ values at the lower boundary of the snowpack was also evident in late-season snow pits at the OP site (Fig. 6). While this may be related to the input of isotopically heavy groundwater, this effect has not been observed directly.

At the OP site in 2005/06 (Fig. 6), there was little structural change to the $\delta^{18} \mathrm{O}$ profiles in the first three snow pits up to OP406. In subsequent snow pits, $\delta^{18} \mathrm{O}$ profiles were progressively smoothed and trended to the most positive $\delta^{18} \mathrm{O}$ values at the ground-snow interface. In OP706, there was a distinct loss of variability in the $\delta^{18} \mathrm{O}$ profile throughout the snowpack. The temperature profile of this snow pit was close to isothermal, and the standard deviation in $\delta^{18} \mathrm{O}$ decreased from $2.7 \%$ in OP606 to $2.1 \%$ in OP706.

There was also a marked shift in $\delta^{18} \mathrm{O}$ in the lowest layers of snow in OP706. While the lowest $100 \mathrm{~mm}$ of SWE in OP606 averaged $-19.8 \%$, this decreased to $-22.1 \%$ in OP706, and only the lowest sample (at $18 \mathrm{~mm}$ depth) remained within $2 \%$ of OP606 values. As meltwater tends to be depleted in heavy isotopes compared to the remaining

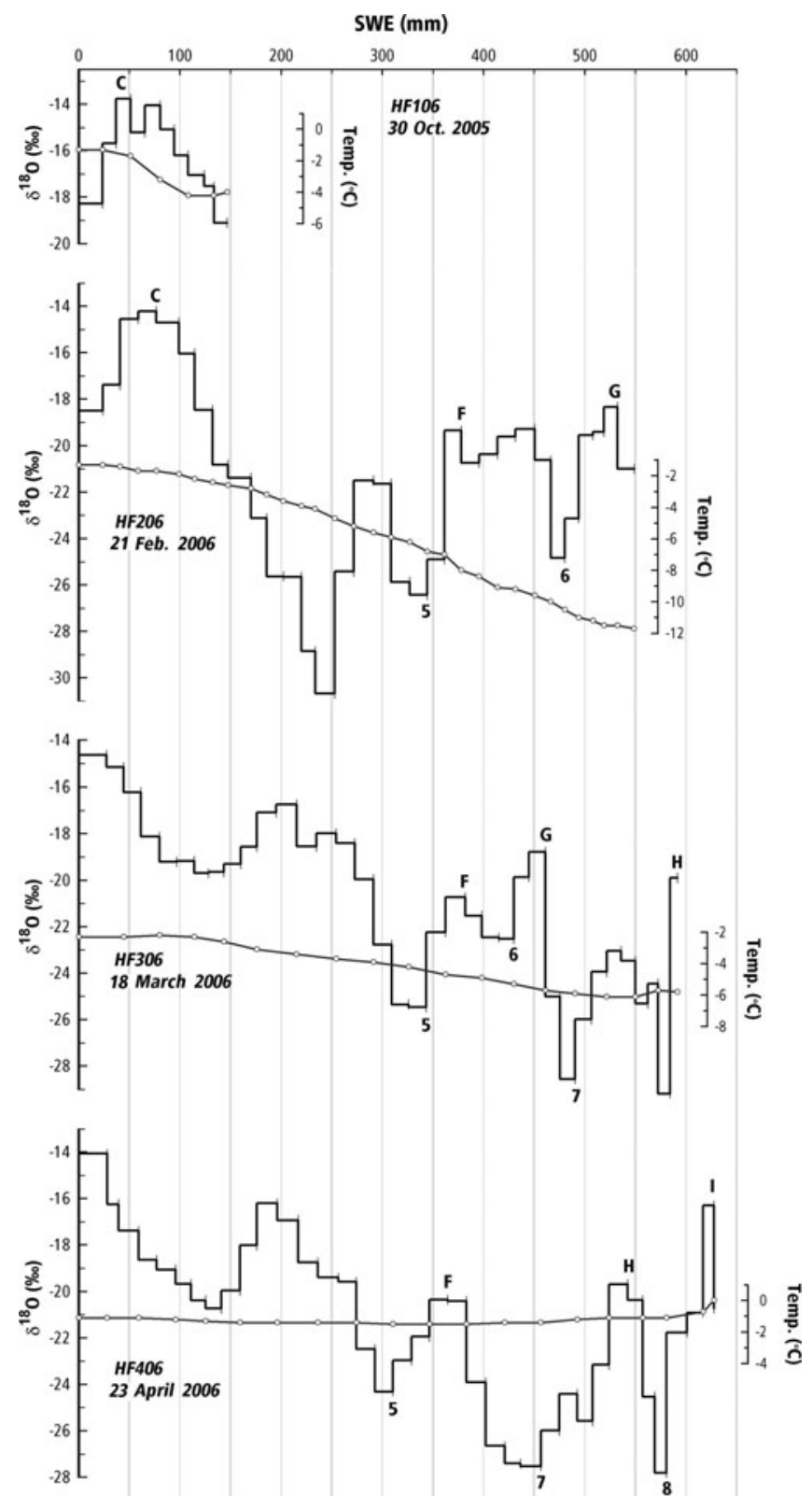

Fig. 5. $\delta^{18} \mathrm{O}$ stratigraphies and temperature profiles of all HF snow pits from the 2005/06 accumulation season.

snowpack (Búason 1972; Hermann and others, 1981), this isotopic depletion may be associated with the introduction of meltwater into the snow matrix. However, as this trend was not reflected in OP806, which was sampled 18 days later and had a mean $\delta^{18} \mathrm{O}$ of $-19.7 \%$ in the lowest $100 \mathrm{~mm}$ of SWE, the effect of meltwater percolation on the isotope stratigraphy is not clear. It could be that this effect is spatially variable over the sampling area or that there is a complex interplay between the input of meltwater and the migration of groundwater into the lower boundary of the snowpack. A thorough investigation of these effects would require highresolution sampling from multiple snow pits.

\section{Vapour transport and depth-hoar formation}

The most likely explanation for the widespread isotopic shifts in the lower reaches of the forefield snowpacks is the input of geothermal heat and consequent depth-hoar formation near the snow-moraine interface. Depth hoar is characterized by large crystals with distinctive skeletal forms 


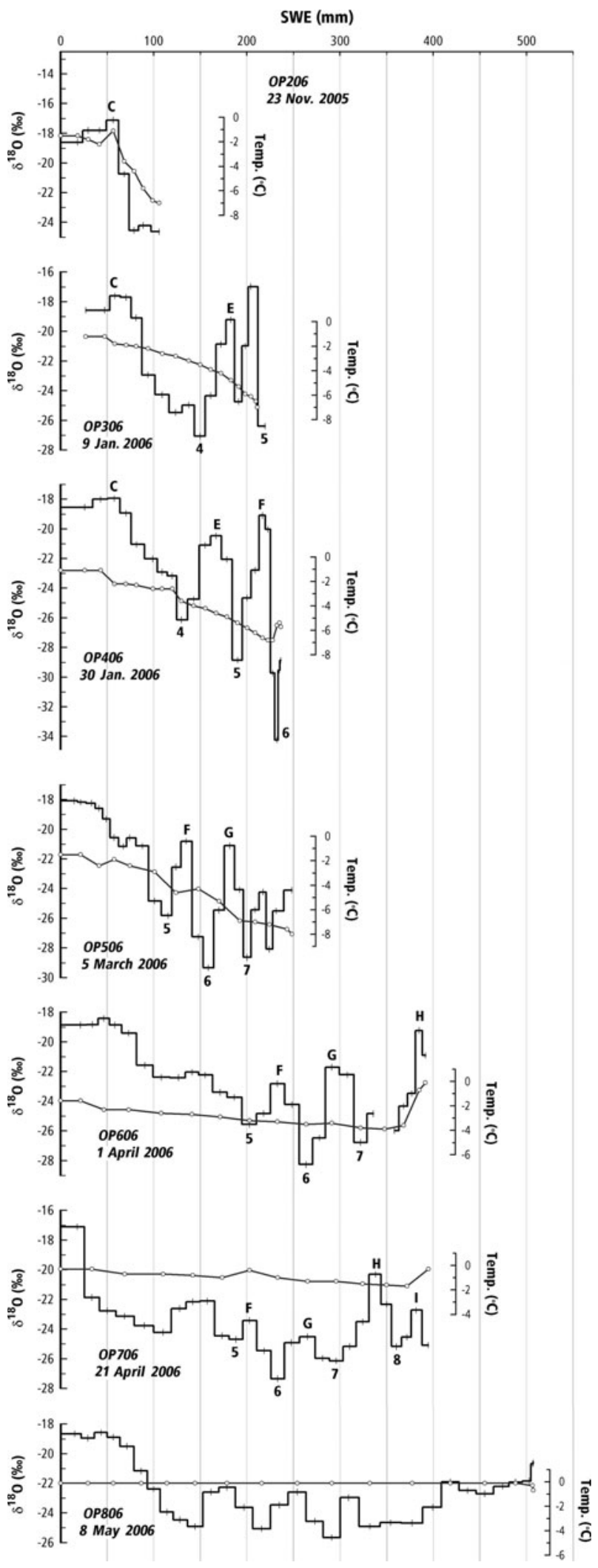

Fig. 6. $\delta^{18} \mathrm{O}$ stratigraphies and temperature profiles of all OP snow pits from the 2005/06 accumulation season. Note that there is no OP106 because there was little snow accumulation at this site at the time the first glacier snow pit (OG106) was sampled.

(Akitaya, 1974) and forms when high temperature gradients $\left(>1{ }^{\circ} \mathrm{Cm}^{-1}\right)$ drive a vapour flux in low-density snow $\left(<300 \mathrm{~kg} \mathrm{~m}^{-3}\right)$ (Colbeck, 1983). The transport of the vapour to higher reaches of the snowpack is thought to occur via a 'hand-to-hand' process (Yosida and others, 1955) whereby each snow grain acts as a source and sink for water vapour; the isotopically light water-vapour molecules are deposited on the lower edge of snow grains while sublimation from the top surface causes a higher concentration of isotopically heavy molecules at this boundary. At a macroscopic scale, there are consequently no net changes to the isotope ratios of the snowpack except in the lower and upper layers where there is a net loss or gain of water vapour (Sommerfeld and others, 1987; Hachikubo and others, 2000).

The effect of vapour transport processes on isotope ratios in depth hoar has been studied in natural snowpacks (Friedman and others, 1991; Satake and Kawada, 1997; Sturm and Benson, 1997) and in laboratory experiments (Sommerfeld and others, 1991; Hachikubo and others, 2000). These studies found that snow subjected to high temperature gradients became enriched in heavy isotopes in the lowest and uppermost layers of the snowpack. In natural snowpacks, this is the result of both the migration of isotopically heavy soil moisture into the snowpack and fractionation during depth-hoar formation, which leaves the vapour depleted in heavy isotopes (Friedman and others, 1991).

The isotopic changes associated with vapour diffusion and recrystallization differ for oxygen and hydrogen. This lends insight into vapour-transport processes that cannot be gleaned from the analysis of one isotopic ratio alone (Friedman and others, 1991; Satake and Kawada, 1997). Isotopic fractionation during in-cloud condensation is a near-equilibrium process, and for unmodified (i.e. fresh) snowfall the line of best fit for $\delta \mathrm{D}-\delta^{18} \mathrm{O}$ data should lie near the global meteoric waterline: $\delta D=8 \delta^{18} \mathrm{O}+10$ (Craig, 1961; Gourcy and others, 2007). The non-equilibrium fractionation associated with vapour diffusion alters this relationship. Excess diffusion of $\mathrm{D}$ relative to ${ }^{18} \mathrm{O}$ theoretically decreases the slope of the $\delta \mathrm{D}-\delta^{18} \mathrm{O}$ regression line in the vapour, and, depending on the location of redeposition, these changes may be transferred to the snow matrix (Sommerfeld and others, 1991).

The differences in the diffusivity of isotopic species may also cause post-depositional changes in the deuterium excess, defined by $d=\delta \mathrm{D}-8 \delta^{18} \mathrm{O}$ (Johnsen and others, 2000). Changes in d-excess have been found to correlate with the depth-hoar level in Antarctica (Satake and Kawada, 1997), and $d$ was observed to decrease systematically during sublimation as $\delta^{18} \mathrm{O}$ increased in the upper layers of a snowpack in the tropical Andes (Stichler and others, 2001).

Changes to each of these measures of post-depositional modification were examined in the 2004/05, 2005/06 and 2006/07 snowpacks. Figure 7 shows changes, in the lowest layers of the snowpack at each site, to the mean $\delta^{18} \mathrm{O}$; the $\delta \mathrm{D}-\delta^{18} \mathrm{O}$ regression line slope; deuterium excess; and the standard deviation of $\delta^{18} \mathrm{O}$. For the HF site, data in Figure 7 represent the lowest $147 \mathrm{~mm}$ of SWE $(n=10)$, which was the total sampled in HF106 on 30 October 2005. This enables us to trace the isotopic development of this snow in subsequent snow pits. It should be noted that the earliest HF snow pits in 2004/05 and 2006/07 were sampled in January. For this reason, we also applied the calculations for these years to the lowest $147 \mathrm{~mm}$ of SWE to permit a direct comparison with the 2005/06 results. At the OP site in 2005/ 06, the earliest snow pit was on 23 November 2005 (OP206). This had a total SWE of $106 \mathrm{~mm}(n=8)$, and so this value was used as the upper boundary for the OP calculations. The average number of samples used for these 

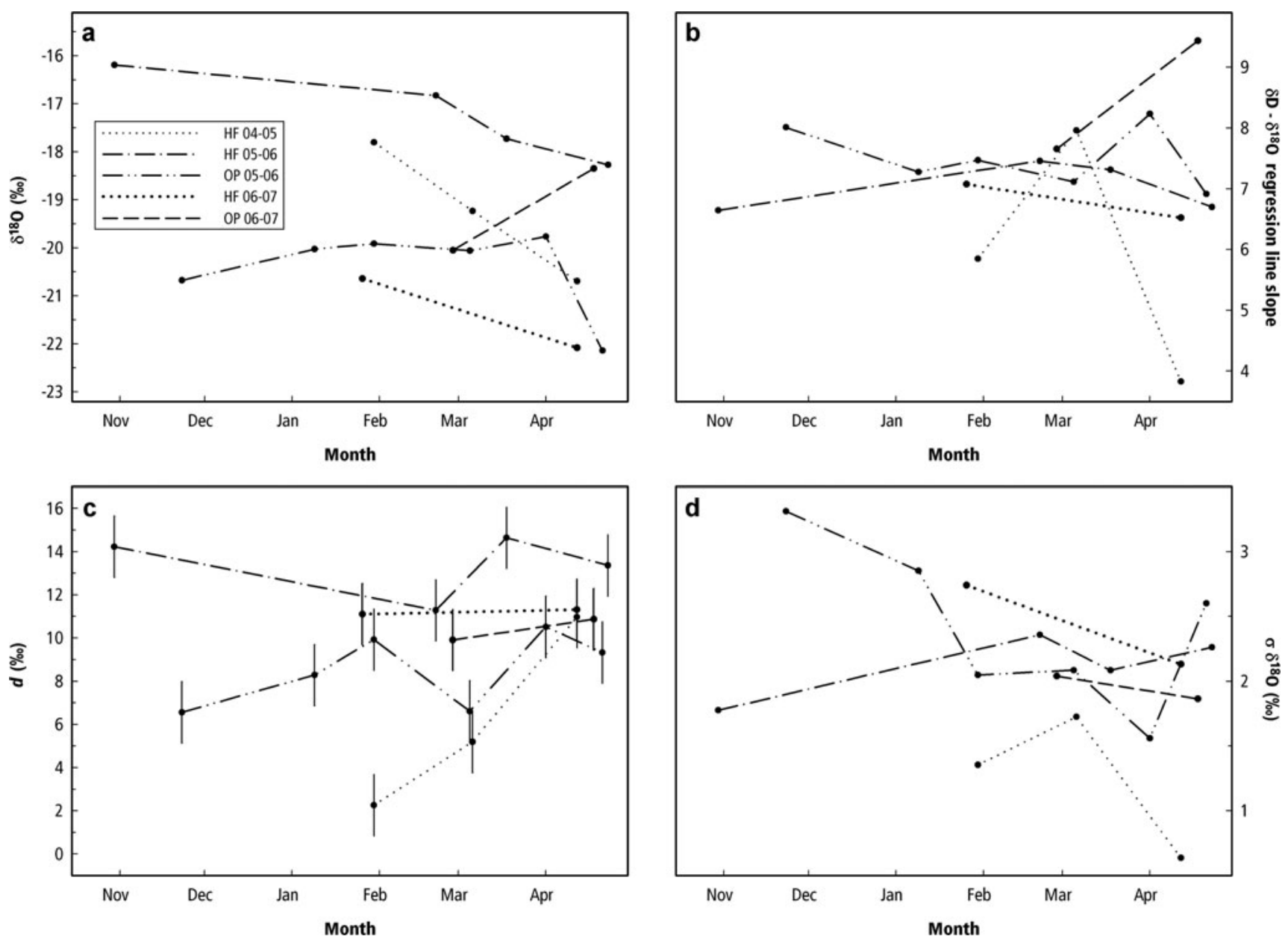

Fig. 7. The seasonal evolution of the early-season snowpack at both field sites. For HF snow pits, this represents $147 \mathrm{~mm}$ of SWE, or the total depth of HF106; for OP snow pits the lowest $147 \mathrm{~mm}$ of SWE was used, which was the total depth of OP106. Each line joins data from consecutive seasonal snow pits for (a) the mean $\delta^{18} \mathrm{O}$; (b) the $\delta \mathrm{D}-\delta^{18} \mathrm{O}$ regression-line slope; (c) deuterium excess $(d)$; and $(\mathrm{d})$ the standard deviation of $\delta^{18} \mathrm{O}$

calculations across all seasons was 6.3 and 6.5 at Haig and Opabin Glaciers respectively.

The results presented in Figure 7 do not provide conclusive isotopic evidence of depth-hoar formation, which would include (1) increasing mean $\delta^{18} \mathrm{O}$; (2) decreasing $\delta \mathrm{D}-$ $\delta^{18} \mathrm{O}$ regression line slopes, and (3) decreasing deuterium excess. As illustrated in Figure $7 \mathrm{a}$, the mean $\delta^{18} \mathrm{O}$ tended to decrease in the lower layers of the snowpack in all seasons, aside from the OP site in 2006/07. The standard error in the estimate of the mean for snow-pit $\delta^{18} \mathrm{O}$ is small $( \pm 0.08 \%$ o $)$ and is not shown in Figure $7 \mathrm{a}$. The $\delta \mathrm{D}-\delta^{18} \mathrm{O}$ regression-line slopes (Fig. 7b) trended to lower values, again with the exception of the OP snowpack in 2006/07. This is the only indicator that follows a trend that is consistent with depthhoar formation. Figure $7 \mathrm{c}$ shows the trends in deuterium excess along with the standard error in the estimate of the mean associated with this parameter $( \pm 1.4 \%)$. There are no discernible trends in $d$ over time in the lower layers of the snowpacks.

Finally, as expected, the standard deviation of $\delta^{18} \mathrm{O}$ tended to decrease over time at both field sites (Fig. 7d), with the exception of the OP and HF snowpacks in 2005/06. At the OP site, the standard deviation decreased until OP706 (cf. Fig. 6), and the standard deviations from snow pits at the $\mathrm{HF}$ site were relatively stable, fluctuating from $1.8 \%$ in HF106 to $2.3 \%$ in HF406. The overall decrease in standard deviation can be partly explained by the smoothing effect of vapour diffusion within the snow matrix and, after the onset of spring melt, by the redistribution of isotopic molecules by percolation processes.

\section{ISOTOPE DIFFUSION MODELLING}

While isotope diffusion in the solid phase is negligible over a single winter season, diffusion does occur in the vapour which occupies the pore space of the seasonal snowpack. This leads to a progressive smoothing of isotope gradients in the snowpack, and the warm temperatures at these midlatitude sites (in contrast to polar firn) potentially give rise to large amounts of diffusion, even in a single season.

We investigate the degree of post-depositional modification associated with vapour diffusion by applying the model of Johnsen and others (2000) to the $\delta^{18} \mathrm{O}$ and $\delta \mathrm{D}$ profiles that were measured in the initial site visit from each season. Let subscript $k$ refer to the isotope species of interest (i.e. $\left.k=\left[{ }^{18} \mathrm{O}, \mathrm{D}\right]\right)$. Assuming that diffusion of $\delta^{18} \mathrm{O}$ and $\delta \mathrm{D}$ in the seasonal snowpack follows

$$
\frac{\partial \delta}{\partial t}=\kappa_{k} \frac{\partial^{2} \delta_{k}}{\partial z^{2}}
$$

we integrate forward in time through the winter to estimate the diffusive smoothing of $\delta^{18} \mathrm{O}$ and $\delta \mathrm{D}$ profiles at each site. 
Effective diffusivities $\kappa_{k}$ are calculated following equation (17) of Johnsen and others (2000):

$$
\kappa_{k}=\frac{N_{\mathrm{w}} e_{\mathrm{si}} \Omega_{\mathrm{ak}}}{R T \alpha_{k} \tau}\left(\frac{1}{\rho}-\frac{1}{\rho_{\mathrm{i}}}\right),
$$

where $N_{w}$ is the molar weight of water, $e_{\mathrm{si}}$ is the saturation vapour pressure over ice, $\Omega_{\mathrm{a} k}$ is the free-air diffusivity of species $k, R$ is the ideal gas-law constant, $T$ is the absolute temperature of the snow, $\alpha_{k}$ is the equilibrium isotopic fractionation factor, $\tau$ is the tortuosity factor for the vapour path length in the pore space (Schwander and others, 1988), $\rho$ is the snow density, and $\rho_{\mathrm{i}}$ is the density of ice. The basis for this expression is well described in Whillans and Grootes (1985) and Johnsen and others (2000), and Helsen and others (2005) have applied it to the seasonal snowpack in Antarctica.

We follow Johnsen and others (2000) in the parameterization of $\tau$ and $\Omega_{\mathrm{ak}}$, while $\alpha_{18} \mathrm{O}(T)$ is from Majoube (1970) and $\alpha_{\mathrm{D}}(T)$ is from Merlivat and Nief (1967). For a snow density of $300 \mathrm{~kg} \mathrm{~m}^{-3}$ and a temperature of $-9^{\circ} \mathrm{C}$, close to the mean winter values in our study, Equation (2) gives effective diffusivities of $\kappa_{18} \mathrm{O}=2.5 \times 10^{-10} \mathrm{~m}^{2} \mathrm{~s}^{-1}\left(7.8 \times 10^{-3} \mathrm{~m}^{2} \mathrm{a}^{-1}\right)$ and $\kappa_{\mathrm{D}}=2.2 \times 10^{-10} \mathrm{~m}^{2} \mathrm{~s}^{-1}\left(6.9 \times 10^{-3} \mathrm{~m}^{2} \mathrm{a}^{-1}\right)$. These values are approximately 100 -fold greater than typical effective diffusivities in polar firn (Johnsen and others, 2000).

We model the post-depositional diffusion in the snowpack using a finite-difference approximation to solve Equation (1), with a moving grid that tracks the snowpack thickness. Snowpack densification is parameterized through a simple model of exponential settling, with densification rates based on density profiles measured during each site visit. Snow temperatures are estimated from $30 \mathrm{~min}$ AWS airtemperature data from each site. Temperatures at depth were not measured, so were estimated by simulating vertical diffusion of temperature into the snowpack:

$$
\frac{\partial T}{\partial t}=\frac{k_{t}}{\rho c} \frac{\partial^{2} T}{\partial z^{2}}
$$

where $k_{t}$ and $c$ are the thermal conductivity and heat capacity of the snow. Measured air temperatures provide the upper boundary condition, and the lower boundary condition is $\partial T / \partial z=0$ at glacier sites, where the underlying glacier surface is isothermal $\left(0^{\circ} \mathrm{C}\right)$, and $\partial T / \partial z=-Q_{\mathrm{G}} / k_{t}$ at the forefield sites, for geothermal heat flux $Q_{\mathrm{G}}$ estimated at $0.05 \mathrm{~W} \mathrm{~m}^{-2}$.

Figure 8 illustrates the effects of vapour diffusion on isotope profiles in the lower snowpack at the HG site in the 2005/06 accumulation season. The dashed lines represent the original (measured) isotope profile from 30 October 2005 (HG106), and the solid lines correspond to the modelled (diffused) profiles on subsequent site visits on 21 February, 18 March and 23 April 2006. The integration runs from 1 November 2005 to 30 April 2006, and we present only the lowest $350 \mathrm{~mm}$ of the snowpack, which was the SWE sampled in HG106. Snow accumulation above this level was prescribed according to snowpack observations, with temperature simulated in the upper layers as part of the isotope diffusion modelling.

The minima and maxima in the initial isotope profile are highly smoothed, with modelled shifts in $\delta^{18} \mathrm{O}$ and $\delta \mathrm{D}$ of up to $2 \%$ and $14 \%$, respectively. Average $\delta^{18} \mathrm{O}$ and $\delta \mathrm{D}$ values in the lower snowpack vary by less than $0.5 \%$ and $3 \%$, respectively. Shifts in deuterium excess are less than $0.2 \%$.
This result is unsurprising, as vapour diffusion serves primarily to redistribute molecules within the snowpack.

Based on diffusion modelling in the lower (early-season) snowpack at the other glacier and forefield sites, diffusive smoothing of the isotope stratigraphy and diffusion-related shifts in mean snowpack $\delta^{18} \mathrm{O}$ and $\delta \mathrm{D}$ were similar in magnitude at all sites. There was no systematic modelled increase or decrease in $\delta^{18} \mathrm{O}$ and $\delta \mathrm{D}$ in the lower snowpack as a result of vapour diffusion; shifts in mean values varied in sign and were less than the observed isotopic changes at the forefield sites.

These results suggest that vapour diffusion may induce significant post-depositional modification via smoothing of isotopic gradients and isotope redistribution within the snowpack, but there is no significant alteration of the bulk isotope content of the lower snowpack. We found this result at both glacier and forefield sites. The observed snowpack isotopic evolution through the winter is not consistent with diffusive smoothing, so other processes are likely responsible for most of the post-depositional modification. We also note that the modelled diffusion is probably excessive: peaks and gradients in the data survive the winter more than the theoretical diffusion would suggest. Vapour diffusivities in this relatively low-density, warm seasonal snowpack may be less than expected on the basis of parameterizations crafted to describe polar firn.

\section{SUMMARY}

There was a significant amount of post-depositional modification to $\delta^{18} \mathrm{O}$ profiles at forefield sampling locations, particularly in the lower snowpack above the ground-snow interface. We postulate that the geothermal heat flux into the base of the snowpack at these sites plays a major role in promoting vapour transport and local redistribution of water molecules. This may occur alongside the input of isotopically heavy groundwater (or groundwater vapour) into the base of the snowpack, but this has not been quantified or observed directly.

The post-depositional modification observed at forefield sites does not consistently conform to trends expected from vapour transport and depth-hoar formation such as a local increase in $\delta^{18} \mathrm{O}$, decreasing $\delta \mathrm{D}-\delta^{18} \mathrm{O}$ slopes and decreasing deuterium excess. While some of these parameters provide evidence of vapour diffusion, this is not consistent at all sites or between accumulation seasons. The application of a diffusion model to isotopic data from these sites tends to overestimate the degree of smoothing that was observed in late-season snow pits, but the overall pattern of postdepositional modification is not consistent with diffusion. It seems that isotopic changes at these sites are a result of the interplay between a number of processes. A detailed stratigraphic investigation coupled with high-resolution isotopic sampling could lend additional insight into postdepositional processes at these sites.

In contrast, there was minimal post-depositional modification to the seasonal $\delta^{18} \mathrm{O}$ profiles at the glacier sites. Key stratigraphic features identified during each accumulation season were preserved until the onset of spring melt throughout the entire snowpack at both sites. It is thought that the insulating layer of ice at the base of these snowpacks dampens the movement of water vapour and restricts the input of geothermal heat. In addition to the intra-seasonal stability in the isotope stratigraphies at these sites, the 

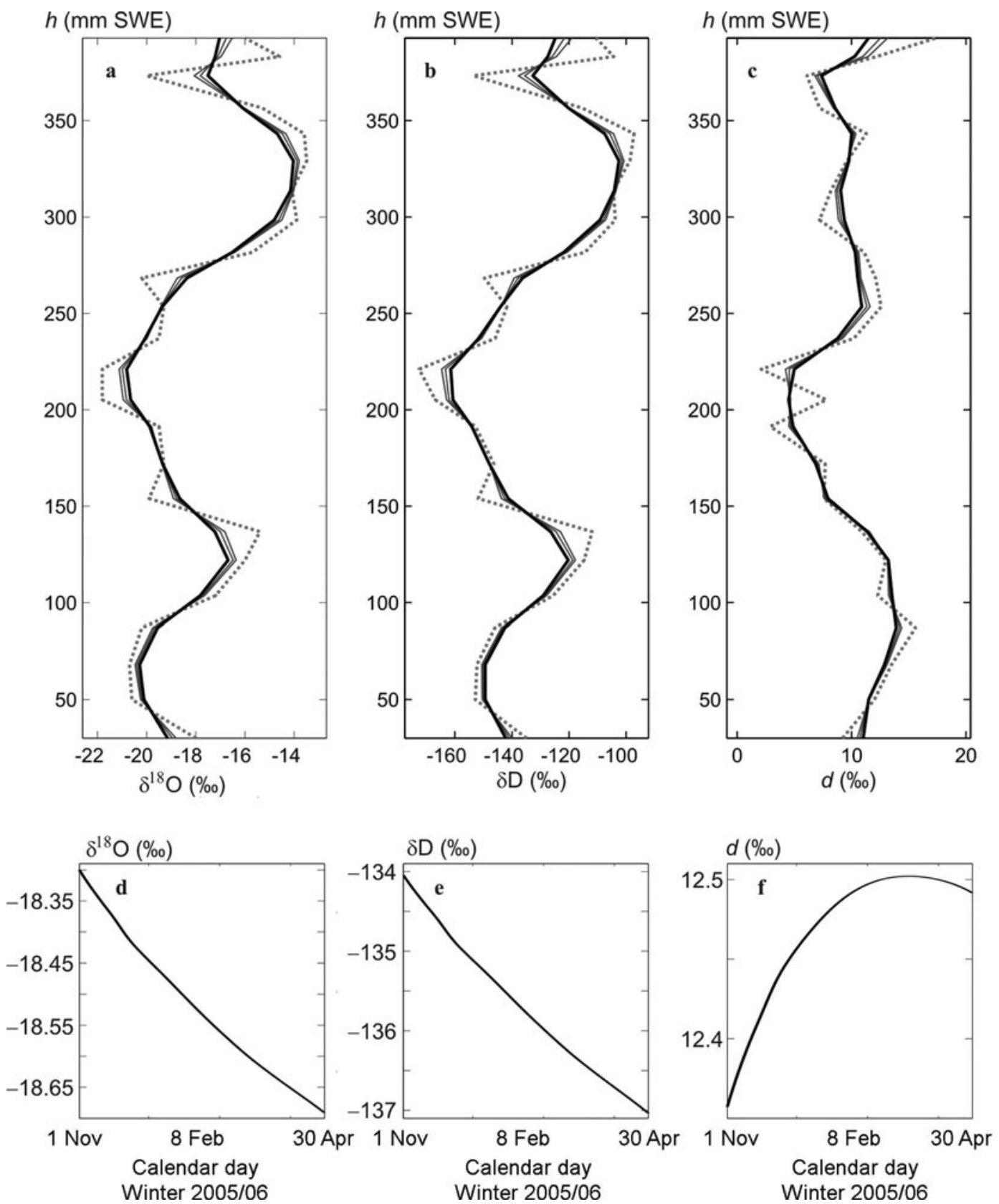

Fig. 8. (a-c) The modelled effects of diffusion on $\delta^{18} \mathrm{O}(\mathrm{a}), \delta \mathrm{D}(\mathrm{b})$ and deuterium excess (c) in the lower $350 \mathrm{~mm}$ of SWE at the Haig Glacier site (HG) from 1 November 2005 to 30 April 2006. The dashed line is the original isotope profile, and the solid lines correspond to modelled profiles on subsequent site visits. $(\mathrm{d}-\mathrm{f})$ The changes in $\delta^{18} \mathrm{O}(\mathrm{d}), \delta \mathrm{D}(\mathrm{e})$ and deuterium excess (f) over the integration period.

structure of the $\delta^{18} \mathrm{O}$ profiles at the $\mathrm{HG}$ and OG sites was comparable throughout all three accumulation seasons. The concordance between isotope records of winter snowfall at sites $160 \mathrm{~km}$ apart in the Canadian Rocky Mountains suggests that the $\delta^{18} \mathrm{O}$ stratigraphy of alpine snowpacks is the result of regional synoptic controls.

These findings suggest that, although considerable postdepositional modification was observed at forefield sites, the isotopic signatures of individual accumulation events tend to remain intact prior to spring melt at glacier sites. Follow-up research uses site-specific snow accumulation and meteorological data to relate the isotopic stratigraphies of lateseason snow pits to specific synoptic conditions (Sinclair and Marshall, unpublished information). The complete winter snowpack stratigraphy can be interpreted in terms of weather systems that dominate the seasonal moisture supply, offering insight into the origin and transport of winter precipitation in the Canadian Rocky Mountains. On longer timescales, an understanding of these relationships can provide insight into how changes in dominant storm trajectories may affect snow accumulation and glacier mass balance in the region.

\section{ACKNOWLEDGEMENTS}

We thank the many people who assisted us with fieldwork over the course of this study, particularly J.L. Hood, T. Moran and B. Horton. We also acknowledge the ongoing collaboration at Lake O'Hara (Opabin Glacier) from M. Hayashi and his research group at the University of Calgary and assistance from S. Taylor at the University of Calgary Stable Isotopes Laboratory. This study was supported by grants from 
the Natural Sciences and Engineering Research Council (NSERC) of Canada and the Canadian Foundation for Climate and Atmospheric Sciences. Comments from two anonymous reviewers are also gratefully acknowledged.

\section{REFERENCES}

Akitaya, E. 1974. Studies on depth hoar. Contrib. Inst. Low Temp. Sci., Ser. A, 26

Bolzan, J.F. and V.A. Pohjola. 2000. Reconstruction of the undiffused seasonal oxygen isotope signal in central Greenland ice cores. J. Geophys. Res., 105(C9), 22,095-22,106.

Búason, T. 1972. Equation of isotope fractionation between ice and water in a melting snow column with continuous rain and percolation. J. Glaciol., 11(63), 387-405.

Colbeck, S.C. 1983. Theory of metamorphism of dry snow. J. Geophys. Res., 88(C9), 5475-5482.

Cooper, L.W. 1998. Isotopic fractionation in snow cover. In Kendall, C. and J.J. McDonnell, eds. Isotope tracers in catchment hydrology. New York, etc., Elsevier, 119-136.

Craig, H. 1961. Isotopic variations in meteoric waters. Science, 133(3465), 1702-1703.

Dansgaard, W. 1964. Stable isotopes in precipitation. Tellus, 16(4), 436-468.

Epstein, S. and T. Mayeda. 1953. Variation of $\mathrm{O}^{18}$ content of waters from natural sources. Geochim. Cosmochim. Acta, 4(5), 213-224.

Fisher, D.A., R.M. Koerner, W.S.B. Paterson, W. Dansgaard, N. Gundestrup and N. Reeh. 1983. Effect of wind scouring on climatic records from ice-core oxygen-isotope profiles. Nature, 301(5897), 205-209.

Friedman, I., C. Benson and J. Gleason. 1991. Isotopic changes during snow metamorphism. In Taylor, H.P., Jr, J.R. O'Neill and I.R. Kaplan, eds. Stable isotope geochemistry: a tribute to Samuel Epstein. Washington, DC, Geochemical Society, 211221. (Special Publication 3.)

Gourcy, L., M. Groening and P.K. Aggarwal. 2007. Stable oxygen and hydrogen isotopes in precipitation. In Aggarwal, P.K., J.R. Gat and K.F.O. Froehlich, eds. Isotopes in the water cycle: past, present and future of a developing science. Dordrecht, etc., Springer, 39-51.

Hachikubo, A., S. Hashimoto, M. Nakawo and K. Nishimura. 2000. Isotopic mass fractionation of snow due to depth hoar formation. Polar Meteorol. Glaciol., 14, 1-7.

Helsen, M.M., R.S.W. van de Wal, M.R. van den Broeke, D. van As, H.A.J. Meijer and C.H. Reijmer. 2005. Oxygen isotope variability in snow from western Dronning Maud Land, Antarctica and its relation to temperature. Tellus, 57B(5), 423-435.

Herrmann, A., M. Lehrer and W. Stichler. 1981. Isotope input into runoff systems from melting snow covers. Nord. Hydrol., 12(4-5), 309-318.

Johnsen, S.J., H.B. Clausen, K.M. Cuffey, G. Hoffmann, J. Schwander and T. Creyts. 2000. Diffusion of stable isotopes in polar firn and ice: the isotope effect in firn diffusion. In Hondoh, T., ed. Physics of ice core records. Sapporo, Hokkaido University Press, 121-140.

Judy, C., J. Meiman and I. Friedman. 1970. Deuterium variations in an annual snowpack. Water Resour. Res., 6(1), 125-129.
Krouse, H.R. and J.L. Smith. 1972. $\mathrm{O}^{18} / \mathrm{O}^{16}$ abundance variations in Sierra Nevada snowpacks and their use in hydrological research. IASH Publ. 107 (Symposium at Banff 1972 - Role of Snow and Ice in Hydrology), 24-38.

Majoube, M. 1970. Fractionation factor of ${ }^{18} \mathrm{O}$ between water vapour and ice. Nature, 226(5252), 1242.

Merlivat, L. and G. Nief. 1967. Fractionnement isotopique lors des changements d'état solide-vapeur et liquide-vapeur de I'eau à des temperatures inférieures à $0^{\circ} \mathrm{C}$. Tellus, 19(1), 122-127.

Moser, H. and W. Stichler. 1975. Deuterium and oxygen-18 contents as an index of the properties of snow covers. IAHS Publ. 114 (Symposium at Grindelwald 1974 - Snow Mechanics), 122-135.

Naftz, D.L., D.D. Susong, L.D. Cecil and P.F. Schuster. 2004. Variations between $\delta^{18} \mathrm{O}$ in recently deposited snow and on-site air temperature, Upper Fremont Glacier, Wyoming. In Cecil, L.D., J.R. Green and L.G. Thompson, eds. Earth paleoenvironments: records preserved in mid- and low-latitude glaciers. Dordrecht, etc., Kluwer, 217-234.

Neumann, T.A., E.D. Waddington, E.J. Steig and P.M. Grootes. 2005. Non-climate influences on stable isotopes at the Taylor Mouth, Antarctica. J. Glaciol., 51(173), 248-258.

Ommanney, C.S.L. 2002. Glaciers of the Canadian Rockies. In Ferrigno, J. and R.S. Williams, Jr, eds. Satellite image atlas of glaciers of the world. USGS Prof. Pap. 1386-J, J199-J289.

Satake, H. and K. Kawada. 1997. The quantitative evaluation of sublimation and the estimation of original hydrogen and oxygen isotope ratios of a firn core at East Queen Maud Land, Antarctica. Bull. Glacier Res. 15, 93-97.

Schwander, J., B. Stauffer and A. Sigg. 1988. Air mixing in firn and the age of the air at pore close-off. Ann. Glaciol., 10, 141-145.

Sommerfeld, R.A., I. Friedman and M. Nilles. 1987. The fractionation of natural isotopes during temperature gradient metamorphism of snow. In Jones, H.G. and W.J. Orville-Thomas, eds. Seasonal snowcovers: physics, chemistry, hydrology. Dordrecht, etc., D. Reidel Publishing Co., 95-105. (NATO ASI Series C: Mathematical and Physical Sciences 211.)

Sommerfeld, R.A., C. Judy and I. Friedman. 1991. Isotopic changes during the formation of depth hoar in experimental snowpacks. In Taylor, H.P., Jr, J.R. O'Neill and I.R. Kaplan, eds. Stable isotope geochemistry: a tribute to Samuel Epstein. Washington, DC, Geochemical Society, 205-209. (Special Publication 3.)

Stichler, W. and U. Schotterer. 2000. From accumulation to discharge: modification of stable isotopes during glacial and post-glacial processes. Hydrol. Process., 14(8), 1423-1438.

Stichler, W., U. Schotterer, K. Fröhlich, P. Ginot, C. Kull and H.W. Gäggeler. 2001. The influence of sublimation on stable isotope records recovered from high altitude glaciers in the tropical Andes. J. Geophys. Res., 106(D19), 22,613-22,620.

Sturm, M. and C.S. Benson. 1997. Vapor transport, grain growth and depth-hoar development in the subarctic snow. J. Glaciol., 43(143), 42-59.

Whillans, I.M. and P.M. Grootes. 1985. Isotopic diffusion in cold snow and firn. J. Geophys. Res., 90(D2), 3910-3918.

Yosida, Z. and 6 others. 1955. Physical studies on deposited snow. I. Thermal properties. Contrib. Inst. Low Temp. Sci., Ser. A, 7, 19-74. 